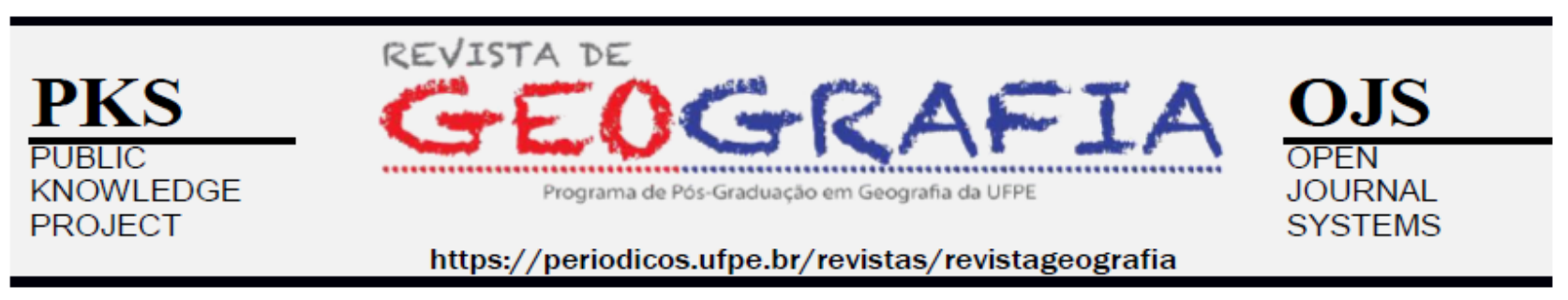

\title{
PAISAGENS NATURAIS DO NORDESTE BRASILEIRO NOS LIVROS DIDÁTICOS DE GEOGRAFIA
}

\author{
Otávio Augusto de Oliveira Lima Barra ${ }^{1}$, Fredson Pereira da Silva ${ }^{2}$, Danilo Vieira dos \\ Santos $^{3}$, Andrea Almeida Cavalcante ${ }^{4}$, Fábio Perdigão Vasconcelos ${ }^{5}$
}

\begin{abstract}
${ }^{1}$ Universidade Estadual do Ceará (UECE). Programa de Pós-graduação em Geografia (ProPGeo). E-mail: otaviolima19@hotmail.com, Orcid http://orcid.org/0000-0002-8147-8000

${ }^{2}$ Universidade Estadual do Ceará (UECE). Programa de Pós-graduação em Geografia (ProPGeo). Email:fredsonsilvap@gmail.com,Orcid http://orcid.org/0000-0003-1363-948X

${ }^{3}$ Universidade Estadual do Ceará (UECE). Programa de Pós-graduação em Geografia (ProPGeo). E-mail: danilovieira841@gmail.com,Orcid https://orcid.org/0000-0001-5956-7456

${ }^{4}$ Universidade Estadual do Ceará (UECE). Programa de Pós-graduação em Geografia (ProPGeo). Email:andrea.cavalcante@uece.br, Orcid http://orcid.org/0000-0003-3291-8855

${ }^{5}$ Universidade Estadual do Ceará (UECE). Programa de Pós-graduação em Geografia (ProPGeo). E-mail: fabioperdigao@gmail.com,Orcid http://orcid.org/0000-0002-0388-4628
\end{abstract}

Artigo recebido em 06/07/2021 e aceito em 12/09/2021

\section{RESUMO}

Os livros didáticos seguem padrões estabelecidos pelos parâmetros curriculares ora vigentes no país. Por serem obras desenvolvidas para atender o grande quantitativo de demandas da educação pública, muitas especificidades regionais e culturais são, em muitas vezes, pouco contempladas por isso a escolha desses conteúdos sobre litoral e caatinga. Assim, o objetivo central deste artigo é analisar a abordagem dos conteúdos relacionados aos ecossistemas litoral e caatingas em livros didáticos (LDs) de Geografia no Ensino Básico. O estudo é do tipo documental - aqui livros didáticos do Ensino Fundamental II Os resultados apontaram que, na análise do litoral no LD1, as definições conceituais dos sistemas oceânicos sobrepujaram a abordagem das relações homem-meio, bastantes relevantes nas regiões costeiras, fato que se assemelha ao que foi analisado no LD2. No LD 3 foi apresentado apenas um mapa da região Nordeste, mostrando a degradação dos biomas brasileiros, dando pouca atenção à caatinga e no LD 4, estimulou-se o uso das plantas da caatinga para uso farmacológico e consumo humano mencionando a associação do relevo com a vegetação da caatinga. A análise dos 4 livros demonstrou que eles carecem de uma maior contextualização dos assuntos físicos abordados, que perpasse a mera reprodução de conteúdo.

Palavras-chave: Educação Contextualizada; Geografia Ambiental; Currículo Escolar; Litoral e Caatinga. 


\title{
NATURAL LANDSCAPES OF NORTHEAST BRAZIL IN GEOGRAPHY TEACHING BOOKS
}

\begin{abstract}
The textbooks follow standards established by the curricular parameters now in force in the country. Because they are books developed to meet the large number of demands of public education, many regional and cultural specificities are often poorly contemplated, hence the choice of these contents on the coast and caatinga. Thus, the central objective of this article is to analyze the approach of contents related to the coastal and caatinga ecosystems in Geography textbooks (LDs) for Basic Education. The results pointed out that, in the analysis of the coastline in LD1, the conceptual definitions of the oceanic systems outweighed the approach to manenvironment relations, quite relevant in coastal regions, a fact that is similar to what was analyzed in LD2. In LD 3, only a map of the Northeast region was presented, showing the degradation of the Brazilian biomes, giving little attention to the caatinga, and in LD 4, the use of caatinga plants for pharmacological use and human consumption was encouraged, mentioning the association of the relief with the caatinga vegetation. The analysis of the four books showed that they lack a greater contextualization of the physical issues addressed, which goes beyond the mere reproduction of content.

Keywords: Contextualized Education. Environmental Geography. School curriculum. Coastal and Caatinga.
\end{abstract}

\section{INTRODUÇÃO}

O espaço geográfico - objeto de estudo da Geografia - possui uma inerente dualidade de análise, a saber: a natureza e a sociedade. Durante décadas, as discussões que permearam a dicotomia geografia física versus geografia humana protagonizou o cotidiano geográfico acadêmico. $\mathrm{Na}$ atualidade, devido a uma grave crise socioambiental instalada e alastrada no planeta, esse embate pretende ser superado, tendo no ideário ambiental, uma saída relevante que supere essa dualidade intrínseca.

No cotidiano escolar, os aspectos socioambientais se acumulam nos livros didáticos, sendo necessária uma percepção do professor para que se contextualize os assuntos abordados.

Oliveira (2002) pontua que é necessária uma contextualização dos conteúdos geográfícos para que advenha uma construção própria de sua aprendizagem pelos discentes. É importante a escolha certa de alternativas de aprendizagem na construção do conhecimento e fortalecimento do saber.

O ensino de Geografia contribui e desenvolve a compreensão do espaço e do tempo, fazendo com que os alunos tenham uma leitura da totalidade do mundo e dos seus intercâmbios, apropriandose dos conhecimentos para crescimento pessoal (SELBACH, 2010).

Para tal compreensão da totalidade do mundo entre sociedade e natureza e seus intercâmbios, a análise da paisagem torna-se primordial nessa discussão. A paisagem não é a simples adição de 
elementos geográficos incoerentes. É, em uma determinada porção do espaço, o resultado da combinação dinâmica de elementos naturais e socioculturais, que dialogam entre si, formando a paisagem um conjunto indissociável (BERTRAND, 2004; CAVALCANTI, 2018).

Deste modo, trabalhar de maneira crítica e contextualizada é de fundamental importância para a elucidação dos conteúdos em Geografia. Dois desses conteúdos são o litoral e as caatingas: geoambientes relevantes no contexto ambiental, de dinâmicas múltiplas e com alto grau de degradação, sendo, deste modo, objetos de análise em que as relações sistêmicas da natureza e da sociedade se dão de maneira bastante intensificada.

O litoral é o ambiente de interface entre oceano e continente. Banhado em cerca de $8.000 \mathrm{~km}$ pelo Oceano Atlântico, o litoral do Brasil é um dos maiores do planeta e rico do ponto de vista da biodiversidade. Ademais, é nesse megassistema em que as ocupações do território brasileiro foram iniciadas, configurando-se num espaço de intensa urbanização, diversas atividades socioeconômicas, desmatamento do bioma Mata Atlântica, palco de variados conflitos socioambientais e onde estão instaurados muitos dos grandes problemas ambientais existentes no país.

A Caatinga brasileira é uma das regiões mais populosas do mundo, com cerca de 56 milhões de habitantes. A população local desenvolveu estratégias de sobrevivência, usando os recursos naturais desse bioma, com técnicas para representação social, tais como a captação da água da chuva por cisternas para uso humano e animal, para sobrevivência no período de estiagem (ALBUQUERQUE e MELO, 2018). Este bioma vem passando por um processo de degradação pelas ações humanas e mudanças climáticas, demandando ações imediatas, para que as pessoas e a natureza possam caminhar em sua totalidade para uma trajetória mais sustentável (TABARELLI, et al., 2018).

Com isso, como transmitir os conteúdos pertinentes a esses dois importantes biomas brasileiros para alunos do Ensino Básico? E como esses biomas são trabalhados no livro didático, principal e, na maioria das vezes, único recurso à disposição dos professores?

Neste contexto, pretende-se através deste trabalho analisar criticamente a abordagem dos conteúdos relacionados ao litoral e a caatinga em livros didáticos de Geografia do Ensino Básico. 


\section{Fundamentação teórica}

\section{Litoral: definições e currículo}

O Brasil possui mais de $8.000 \mathrm{~km}$ de linha de costa, sem considerar as baías e reentrâncias geomorfológicas, incorporando 17 estados, mais de 400 municípios, incluindo grandes capitais e onde residem aproximadamente $30 \%$ da população brasileira (IBGE, 2010). Tais ambientes possuem uma especial singularidade sob o ponto de vista paisagístico onde coexistem diversos geossistemas, além da rica biodiversidade de fauna e flora.

A múltipla variedade ambiental atribui aos geoambientes costeiros diferentes graus de vulnerabilidade sob o ponto de vista ecodinâmico. A interferência humana nesses ambientes intensifica a fragilidade inerente, acarretando diversos impactos ambientais nessas áreas. A erosão, o lançamento de efluentes, o lixo inadequado, poluição, contaminação, todos somados à intensa ocupação - legitimada ou não pelas políticas de ordenamento territorial - são exemplos de problemáticas presentes nos litorais. Associa-se a esses elementos, os riscos relacionados aos prognósticos de elevação do nível do mar (Figura 1).

Figura 1 - Aterro da Praia de Iracema em Fortaleza, Ceará (à esq.). Efeitos de grande ressaca do mar também na Praia de Iracema.

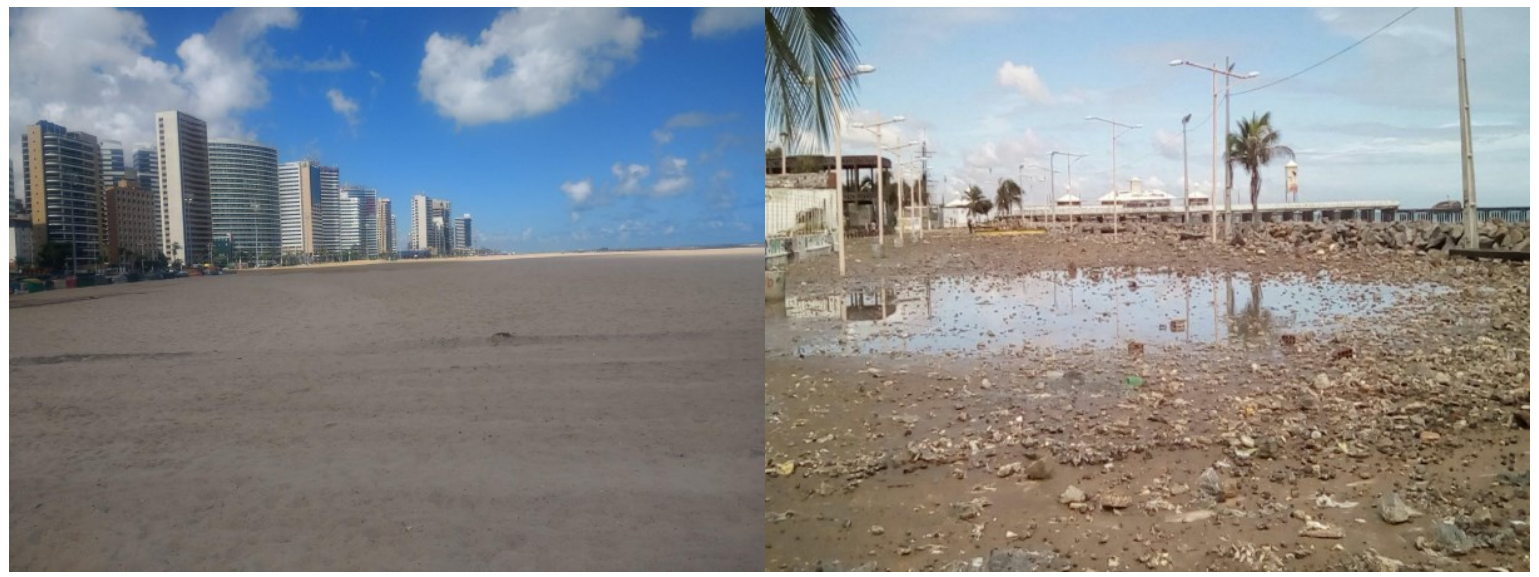

Fonte: Os autores, 2018 e 2019.

Como cita Vasconcelos (2005), a zona costeira é uma região de demasiadas relações sociais, culturais e econômicas estabelecidas dentro de um contexto histórico de uso e ocupação do território brasileiro. Portanto, sua abordagem deve ser além das caracterizações físicas, como é comumente retratada nos livros didáticos nos anos escolares. 
No âmbito escolar, os Parâmetros Curriculares Nacionais - PCNs de 1998 (BRASIL, 1998) trabalham os aspectos do litoral no Eixo 3 "Modernização, Modos de Vida e a Problemática Ambiental" mais especificamente no Tema "O Brasil diante das questões ambientais".

Nessa seção, o PCN aponta itens que devem ser usados como parâmetros para trabalhar o tema mencionado, um deles é o "planejamento ambiental e políticas públicas” e, nesse item, ele insere o Plano Nacional de Gerenciamento Costeiro - PNGC. Esse Plano consiste em uma das principais leis de ordenamento territorial costeiro do Brasil. Anteriormente, o tema "costa" era visto enquanto elemento de referência para o mapeamento de paisagens e regiões brasileiras. Afora esses, não se observa explicitamente o tema em demais partes do documento.

Além disso, com todas essas interações e dinâmicas naturais e humanas na zona costeira, como esses assuntos devem ser abordados na sala de aula de acordo com a nova Base Nacional Comum Curricular - BNCC (BRASIL, 2017), é uma das preocupações que nortearam essa análise. De acordo com a Lei de Diretrizes de Base (LDB, Lei n 9.394/1996), a Base Nacional Comum Curricular tem o papel de nortear os currículos dos sistemas e redes de ensino brasileiras nas escolas públicas e privadas, indo da educação infantil ao ensino médio no país.

Este documento tem como papel principal a orientação do desenvolvimento de competências e habilidades a serem desenvolvidas pelos alunos dos anos letivos das séries correspondentes.

\section{Caatinga: definições e currículo}

O nome "caatinga" é de origem Tupi-Guarani e significa "floresta branca", distingue bem a feição da vegetação no período da seca, quando as folhas caem e apenas os troncos brancos e brilhosos das árvores e arbustos continuam na paisagem seca (PRADO 2003; MAGALHÃES, 2012). Já na literatura internacional, a Caatinga é conhecida como Floresta Tropical Sazonalmente Seca (SDTF) e heterogênea (SILVA et al., 2017).

A Caatinga é um domínio excepcionalmente brasileiro composto por espécies endêmicas (AB'SABER, 2003; WERNECK, 2011). Ela está presente nos estados de Pernambuco, Ceará, Paraíba, Rio Grande do Norte, Paraíba, Piauí, Alagoas, Sergipe, Bahia e no norte de Minas Gerais totalizando uma área de $844.453 \mathrm{~km}^{2}$, adequada a cerca de $11 \%$ do território nacional. Com isso, o domínio da Caatinga tem como atributos, os climas quentes e secos com duas estações bem distintas, a seca e a chuvosa. As chuvas médias anuais variam entre $300-800 \mathrm{~mm}$, com temperaturas médias do ar em torno de $28^{\circ} \mathrm{C}(\mathrm{PRADO}, 2003)$. 
Tabarelli et al., (2018) mencionam que a Caatinga é composta hoje por 3.150 espécies de plantas vasculares, 276 formigas, 386 peixes, 98 anfíbios, 191 répteis, 548 aves e 183 mamíferos, o que atribui à Caatinga o título das florestas secas mais ricas do mundo (Figura 2).

A Caatinga proporciona fisionomias semelhantes com outros domínios localizados em outras regiões do mundo como na Colômbia e Venezuela. No entanto, é uma formação brasileira, apresentando uma paisagem com vegetação arbustiva, ramificada e espinhosa, com muitas euforbiáceas, bromeliáceas e cactáceas (PRADO, 2003; WERNECK, 2011). Mesmo com essa grande diversidade, a Caatinga está no processo de degradação por conta da exploração da madeira, carvão vegetal e mineração.

O desmatamento da Caatinga atinge, atualmente, 46\% de sua área. Degradação que ocorre para dar lugar a agropecuária, agricultura de exportação e mineração de agregados para construção civil, ocasionando o desgaste do solo, diminuição da fauna e da flora, dentre outros problemas (BRASILEIRO, 2009; MAGALHÃES, 2012; SILVA, MOURA, SANTOS, 2018). A degradação citada anteriormente, juntamente com as variações climáticas, resulta no aparecimento de áreas com avançado risco de desertificação (SANTOS, GALVÍNCIO, 2013). A Caatinga está em terceiro lugar entre os biomas/domínios na hierarquia de degradação no Brasil, detrás da Floresta de Mata Atlântica e do Cerrado (SOUZA, ARTIGA, LIMA, 2015).

Figura 2 - Vegetação de Caatinga em encosta de blocos de rocha gnaisse com facheiro (Pilosocereus pentaedrophorus) na Serra da Santa, Petrolina-Pernambuco.

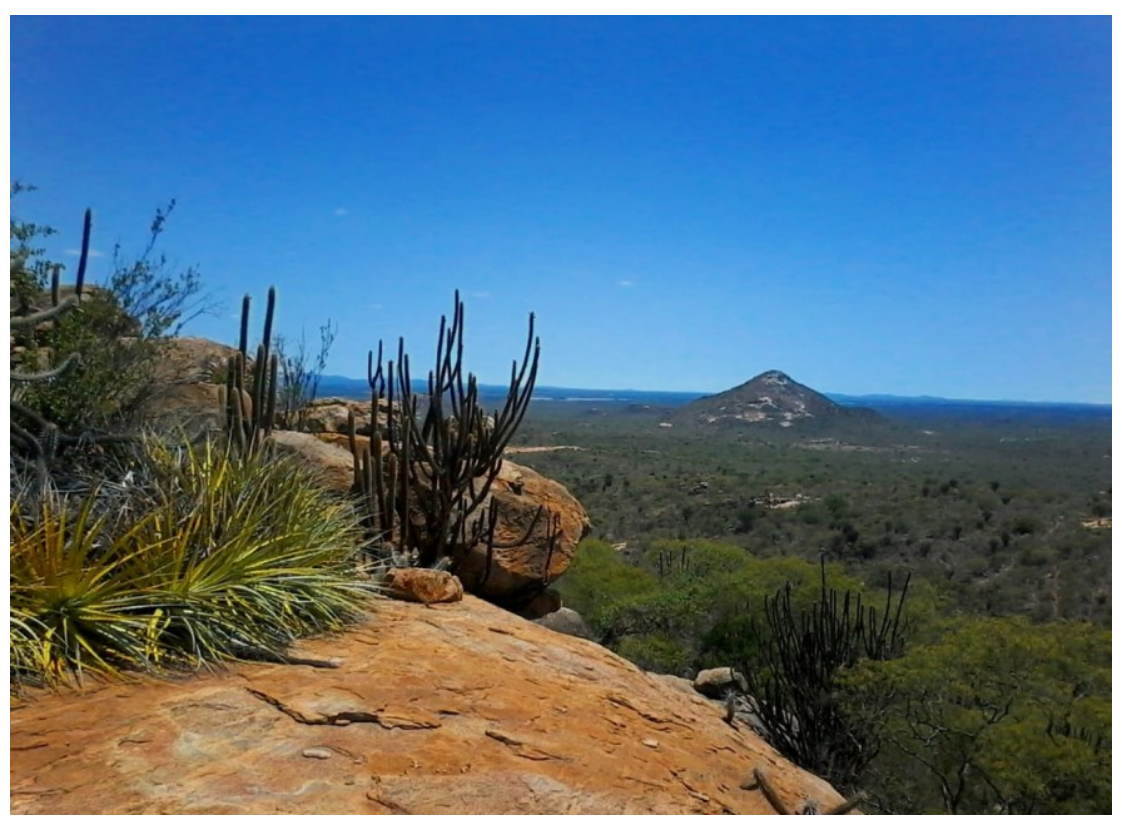

Fonte: Os autores, 2019. 
Devido ao desmatamento, o governo criou unidades de conservação no âmbito Federal e Estadual, pois a Caatinga possui espécies endêmicas, carecendo de estudos de conservação e preservação (VELLOSO, SAMPAIO, PAREYN, 2002). Existe 135 áreas geoambientais na Caatinga, que agrupadas, formam nove ecorregiões, incluindo uma nova área chamada São Francisco Gurgéia para destacar a singularidade da floresta tropical sazonalmente seca (SILVA, et al., 2017).

Neste aspecto, há precisão de trabalhar os conteúdos das caatingas, em sala de aula. Deste modo, surge a dificuldade de encontrar livros que destaquem as peculiaridades ambientais; socias e problemas das caatingas no ambiente escolar.

Castrogiovanni e Goulart (2002) destacam que o livro auxilia o trabalho docente na escola. Entretanto, não se deve ficar preso apenas a ele, podem ser buscadas outras opções. Ainda assim, para se eleger um bom livro, deve-se levar em consideração esses critérios: fidedignidade das afirmações, estímulo à criatividade, representação cartográfica, uma abordagem da realidade e o espaço em sua totalidade.

Nos Parâmetros Curriculares Nacionais de Geografia, é pontuado que os discentes, ao estudar a Caatinga, necessitam entender a estrutura da vegetação e seu porte (arbórea, arbustiva e herbácea), como também trabalhar as questões culturais da população, impactos socioambientais, pois nesse ambiente residem cerca de 28,6 milhões de pessoas em 2010, correspondendo a 14,5\% da população brasileira em 1213 municípios, cujos limites se sobrepuseram 50\% ou mais aos limites da Caatinga (BRASIL, 1998; SILVA, et al., 2017).

Callai (2003) comenta que a Geografia que o discente estuda deve fazê-lo entender a realidade que ele está inserido, os fenômenos resultados da vida e do trabalho, relacionado à realidade do aluno, para além das aulas descritivas e distantes. Observando sempre a escala, local, regional e global, a exemplo trabalhando sobre as áreas de Caatinga na sua comunidade, às espécies encontradas, logo após, no semiárido a extensão nos estados no Nordeste do Brasil e no global, áreas parecidas em outros países como o México, África e Austrália.

Callai (op.cit.) retrata ainda que o conhecimento que vem de casa (precedente) deve ser trabalhado na escola, com apoio da Geografia, para ser produzido em um saber científico. A escolha do conteúdo deve estar ligada à realidade do aluno, o ensino da Geografia deve estar ligado ao contexto histórico, para que o discente possa interpretar e entender o mundo para a cidadania e formá lo como cidadão. 
Como também o docente tende avaliar e formular propostas didáticas mais apropriadas para o desenvolvimento do projeto pedagógico na escola num enfoque teórico metodológico (SPÓSITO, 2002).

O trabalho de Silva e Santos (2018) propõem trabalhar a Caatinga de maneira contextualizada, com auxílio de materiais paradidáticos para um melhor entendimento deste domínio e a população que reside na área semiárida.

Já Rocha (2018) analisou três livros didáticos de Geografia, eles possuem pouco conteúdo sobre a Caatinga e descontextualizados. A autora propõe que fosse feita uma maior contextualização nos livros e assuntos sobre preservação e conservação desse bioma, como também atividades de campo, para inserir os discentes na sua realidade e na sua formação social.

\section{METODOLOGIA}

O estudo é do tipo documental, que no campo da abordagem qualitativa, é aquele que trabalha em cima dos inúmeros tipos de documentos produzidos pelo ser humano (GIL, 1999). Esses dados receberam tratamento analítico, os quais foram verificados e/ou reexaminados com vistas a uma interpretação nova ou complementar.

Para estabelecimento dos pontos de análise do conteúdo acerca do litoral e da Caatinga, fezse, primeiramente, uma leitura exploratória das obras alvo do estudo. Os livros didáticos foram adquiridos em escola pública e o outro de uma instituição da rede particular, totalizando 04 materiais (Quadro 1). Para facilitar o apontamento dos livros ponderados, adotou-se a sigla LD, correspondente a um Livro Didático.

Para a concretização das apreciações do conteúdo, foram analisadas citações, textos e/ou ilustrações (gráficos e figuras) referentes ao litoral e à caatinga em livros usados por uma escola pública e outra particular da região nordeste do Brasil. 
Quadro 1 - Quadro de identificação dos livros didáticos analisados.

\begin{tabular}{|c|c|c|c|c|c|c|c|}
\hline Título do livro & Autor & $\begin{array}{c}\text { Editora e } \\
\text { cidade }\end{array}$ & Volume & Ano & Edição & Código & Série \\
\hline Conquista & MOREIRA, I. & $\begin{array}{l}\text { Positivo, } \\
\text { Curitiba }\end{array}$ & 01 & 2014 & 1 & LD1 & $\begin{array}{l}6^{\circ} \text { Ano } \\
\text { Ensino } \\
\text { Funda- } \\
\text { Mental }\end{array}$ \\
\hline LIVRO BNCC & $\begin{array}{c}\text { CHOPINHO. C, } \\
\text { A. }\end{array}$ & Construir & $\begin{array}{c}\text { Não } \\
\text { informa- } \\
\text { do }\end{array}$ & $\begin{array}{l}\text { Não } \\
\text { Infor- } \\
\text { mado }\end{array}$ & 1 & LD2 & $\begin{array}{l}6^{\circ} \text { Ano } \\
\text { Ensino } \\
\text { Funda- } \\
\text { Mental }\end{array}$ \\
\hline Conquista & MOREIRA, I. & $\begin{array}{l}\text { Positivo, } \\
\text { Curitiba }\end{array}$ & 01 & 2014 & 1 & LD3 & $\begin{array}{l}7^{\circ} \text { Ano } \\
\text { Ensino } \\
\text { Funda- } \\
\text { Mental }\end{array}$ \\
\hline $\begin{array}{l}\text { Geografia nos } \\
\text { dias de hoje }\end{array}$ & $\begin{array}{c}\text { GIARDIANO, } \\
\text { C.;ORTEGA, L. } \\
\text { M.; ORTONELA, } \\
\text { J.;CHIANCA, } \\
\text { R.B.;CARVALH } \\
\text { O, V. }\end{array}$ & $\begin{array}{l}\text { Leya, São } \\
\text { Paulo }\end{array}$ & 02 & 2015 & 1 & LD4 & $\begin{array}{l}7^{\circ} \text { Ano } \\
\text { Ensino } \\
\text { Funda- } \\
\text { Mental }\end{array}$ \\
\hline
\end{tabular}

Fonte: Adaptado de Silva e Santos (2018).

\section{RESULTADOS E DISCUSSÃO}

\section{Abordagem do litoral nos livros didáticos}

O LD1 apresenta mais de 30 páginas destinadas ao contexto oceânico, inclusive sendo este o título do capítulo que contempla esse assunto (Figura 3). O tema "litoral" (ou "costa", como é dito no PCN) - definido como a faixa de terra emersa, à beira-mar - e seus derivados, como: geologia e geomorfologia costeiras, a ação humana, já os problemas ambientais foram abordados dentro de um conjunto maior, a saber, as águas oceânicas.

O referido capítulo elenca a descrição dos oceanos, sua distribuição e nomenclatura sobre a Terra; a morfologia oceânica, definição, importância e riqueza dos mares e oceanos; os movimentos do mar (marulhos, ondas e marés), influência dos astros nesses movimentos; riquezas dos mares e oceanos; as ressacas do mar; correntes marinhas; ação hidrodinâmica sobre o relevo terrestre; 
ambientes marinhos como pântanos salgados, manguezais e recifes de corais; traz também alguns pontos acerca da degradação dos ecossistemas marinhos (Figura 4) e plásticos nos oceanos.

Figura 3 - Capa do capítulo do LD1 “Águas Oceânicas”

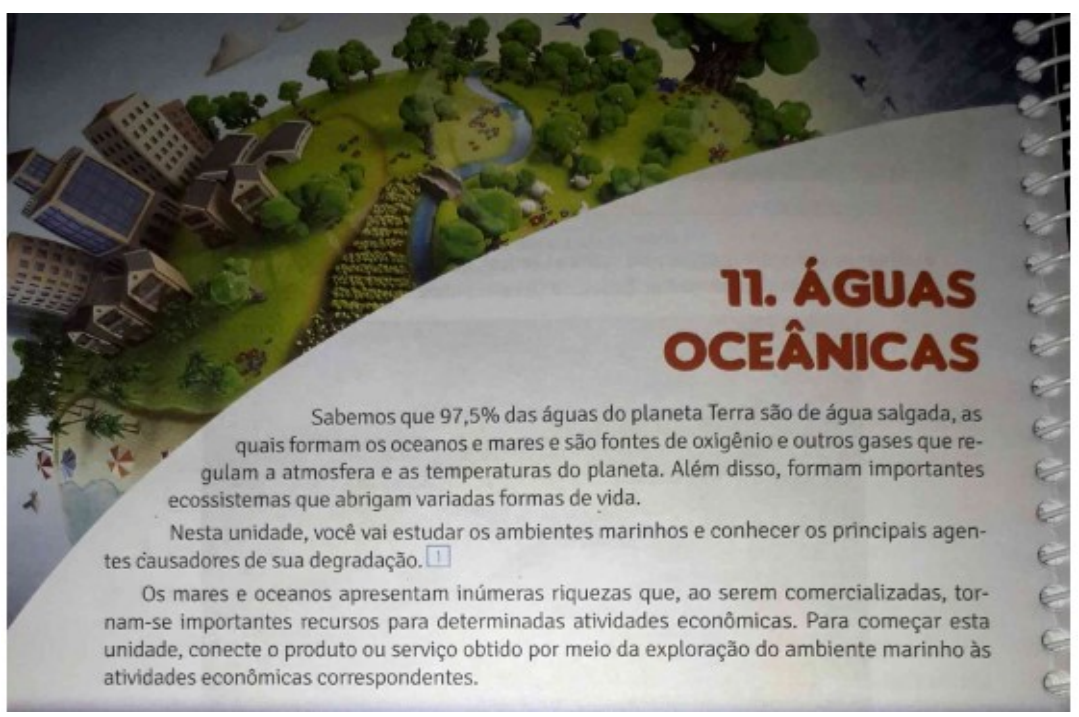

Fonte: Moreira (2014).

Figura 4 - Problemas ambientais descritos no livro
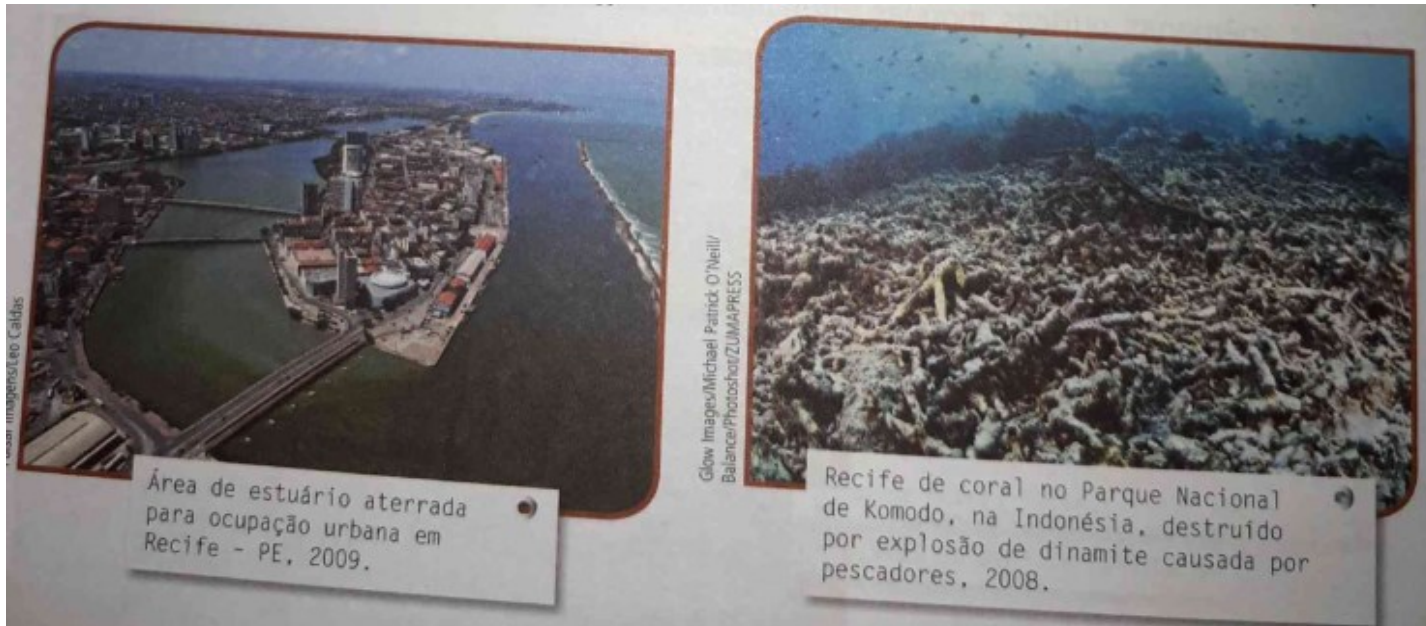

Fonte: Moreira (2014)

Diante dos assuntos expostos, observou-se que as definições dos sistemas ambientais sobrepujaram, em muito, as relações homem-meio. Faltou também um maior enfoque sobre a costa brasileira e nas relações socioambientais no litoral. A observação e a caracterização dos elementos presentes na paisagem é o ponto de partida para uma compreensão mais ampla das relações entre sociedade e natureza (BRASIL, 1998). 
Destaca-se, no entanto, que a definição dos conceitos tem seu lugar e importância no aprendizado, entretanto, a superação do ideário meramente descritivo e mnemônico é fundamental para a formação de seres humanos críticos que se mostrem capazes de mudar a realidade dos locais onde vivem. Uma visão geográfica da realidade urge nos tempos atuais.

Vale pontuar que cerca de $30 \%$ da população brasileira habita na zona costeira brasileira (IBGE, 2010), além disso, no ano de 2015, por exemplo, cerca de R $\$ 1,11$ trilhão de PIB brasileiro se deu através de atividades socioeconômicas ligadas ao mar e a costa (CARVALHO, 2018). Isso implica numa pressão ambiental considerável nesses ambientes, que precisam ser ensinados através dos livros e no cotidiano escolar.

Trabalhar as questões ambientais no Brasil envolve, portanto, um desafio grande do professor na sua compreensão dos processos históricos e geográficos que definiram as políticas públicas que em grande parte são a causa e a consequência dos problemas socioambientais atuais (BRASIL, 1998).

O ensino sobre o mar e a costa mostra-se premente, inclusive na possibilidade de acesso de muitos estudantes que, embora vivam em cidades costeiras, têm raro - ou nenhum - ingresso às praias de seus municípios ou estados. Os currículos, em suas normas e diretrizes, devem estabelecer melhor essa aproximação entre o que se está escrito e a realidade do aluno.

O LD2 apresenta em seu sétimo capítulo apenas 4 páginas de assuntos referentes ao litoral, sendo ainda o capítulo do livro que mais aborda os conteúdos referentes à zona de costa, mesmo que de modo incompleto quanto às suas características relacionando sociedade e natureza.

Dentro das normas da BNCC, não há nenhuma diretriz voltada para a abordagem do litoral no $6^{\circ}$ ano. As descrições sobre as características da região costeira se limitam apenas a sua morfologia derivada de agentes naturais e hidrodinâmicos (Figura 5). 
Figura 5 - Abordagem de litoral nos capítulos 7 e 8 do LD2
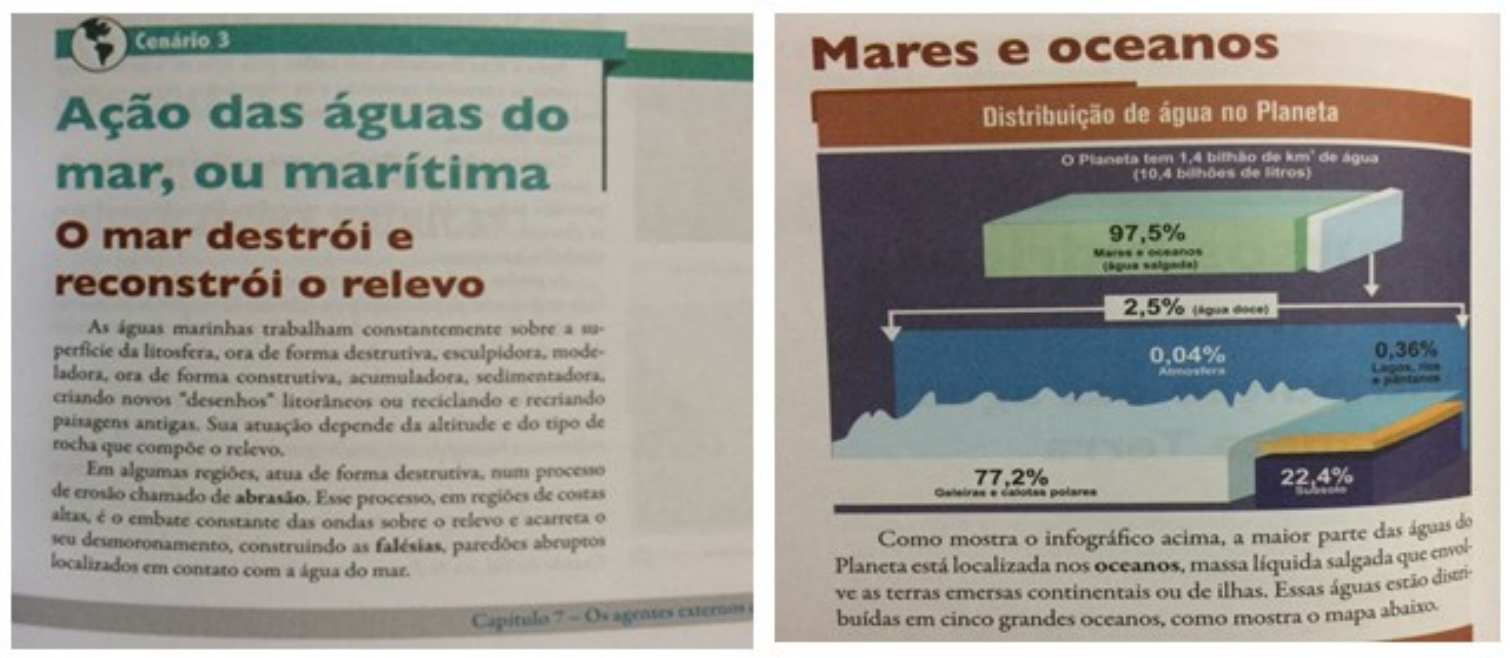

Fonte: Chopinho (sd).

Vale ressaltar que as abordagens da dinâmica ambiental não sejam menos importantes na construção do conhecimento geográfico, mas dentro das discussões propostas no âmbito da Geografia pela BNCC, o homem precisa ser inserido no processo de transformação da paisagem. Essa valorização de aspectos ambientais sem interferências antrópicas flerta com a Geografia tradicionalista que se encarrega de breves descrições superficiais da natureza.

A partir do capítulo sete, onde as habilidades a serem trabalhadas de acordo com a BNCC correspondem a analisar as interações da sociedade com a natureza tendo como base a distribuição dos componentes geográficos, é abordada somente a parte física do litoral, com base na descrição da morfologia praial sendo derivada da ação de forçantes hídricas, como os rios e ação do mar na formação e modelação das praias, não sendo associada a relação do homem como agente transformador do espaço costeiro.

Já no capítulo oito, os mares e oceanos também são citados, mas somente de forma descritiva quanto à sua porcentagem de distribuição pelo globo como massa líquida sem qualquer relação antrópica. Essa breve descrição natural da morfologia costeira na respectiva série exclui um leque de debates do rol da construção e modelação da zona costeira com a participação do homem nesta porção do espaço geográfico.

De acordo com Freitas (2013), o litoral oferece um campo amplo de investigação multidisciplinar, cenário este que serve como base para análise de áreas do conhecimento como a 
História, a Geografia, a Antropologia, a Sociologia, a Economia, e entre outras. A importância de se debater sua construção a partir da relação entre homem e meio provém das interações sociais e econômicas com a zona costeira, envolvendo atividades como a pesca, o turismo, a exploração de recursos, transporte e entre outros.

No documento da Base Nacional Comum Curricular visto como meio de análise dos conteúdos voltados para litoral no material didático em questão, apresentou uma pobre abordagem sobre a zona costeira. Essa abordagem escassa sobre a interação sociedade e litoral revela que a mentalidade marítima, ou como o homem descreve mentalmente o mar, esteja relacionada intimamente a descrições superficiais, sendo mais lembrado como fonte de alimento e de recreação estando mais relacionado ao pescado e ao lazer, desconsiderando sua importância para outros fins (CAMILLO; FILHO, 2006).

A zona costeira, do ponto de vista físico é a estreita faixa terrestre entre o continente e o oceano, e do ponto de vista político envolve todos os sistemas ambientais e econômicos existentes nessa estreita faixa ou que esteja sob sua influência. No Brasil, existem desde comunidades a grandes cidades na região de costa, exercendo influência sobre esse espaço, existindo uma necessidade de estudos voltados para tal sobre as perspectivas futuras no rol das discussões ambientais.

Há de se considerar que abordar a zona costeira para a turma do sexto ano do ensino fundamental não deve ser de forma muito densa, pois os debates em torno do litoral são em algumas perspectivas um pouco complexos, mas é importante que a atuação do homem nas interações com as dinâmicas costeiras estejam associadas, como forma, também, de discutir impactos ambientais em determinados cenários atuais e futuros. O documento da BNCC estabelece que a abordagem no campo da Geografia deva ser estabelecida a relação sociedade e natureza, quando afirma:

Para tanto, no $6^{\circ}$ ano, propõe-se a retomada a identidade sociocultural, do reconhecimento dos lugares de vivência e da necessidade do estudo sobre os diferentes e desiguais usos do espaço para uma tomada de consciência sobre a escala da interferência humana no planeta (BNCC, p. 381).

Entendido isso, não seria o caso de melhor relacionar ações antrópicas e ocupações, conflitos e especulações do espaço costeiro visto que sua abordagem está condicionada apenas a breves descrições físicas e nem tão bem discutidas. Partindo deste ponto de preocupação, foi revisado apenas conteúdos sobre a zona costeira dentro da perspectiva do documento supracitado, devendo considerar que não há nenhuma citação sobre como ou de que forma os professores devam abordar diretamente 
o litoral ou os materiais didáticos devam abordar seus conteúdos. Toda a análise realizada foi baseada em competências genéricas descritas pelo documento que não se aprofunda em algumas problemáticas.

Com isso, o material é insuficiente quanto à sua composição referente ao assunto. Isso pode ser resultado do regimento do documento da $\mathrm{BNCC}$ quanto às suas diretrizes de conteúdos que em alguns aspectos não são firmes nem tão claros. O livro está regido pela BNCC de acordo com a resolução ${ }^{\circ}$ 2, de 22 dezembro de 2017. O ano de publicação não está informado, bem como não há o volume no material. A falta de diretrizes da Base Nacional Comum Curricular - direcionada aos conteúdos voltados para a zona costeira no sexto ano - comprometeram a análise do material.

\section{As caatingas nos livros didáticos}

O LD 3 destaca o conceito da palavra Caatinga "mata branca", e suas características botânicas (porte), e as estações do ano da sua floração no período chuvoso e seco. O LD 3 menciona que a Caatinga pode ser encontrada no Nordeste, particularmente na subregião Sertão, destacando o clima semiárido, como também a questão da degradação pela exploração da madeira para carvão vegetal e setor de biocombustível e a pecuária. Nas atividades são mencionadas apenas questões ligadas ao desenvolvimento do Nordeste e sua hidrografia.

O LD 3 não apresenta figuras relacionadas à Caatinga, apenas um mapa (Figura 6) generalizado a vegetação do Nordeste, dando pouca atenção a esse domínio, apesar da mesma possuir um flora com cerca de 3.150 espécies (TABARELLI et al., 2018), o LD 3 não alude a população e aspectos econômicos da região semiárida, como também o relevo e suas características na abordagem sistêmica. 
Figura 6 - Vegetação da Caatinga no mapa do LD 3

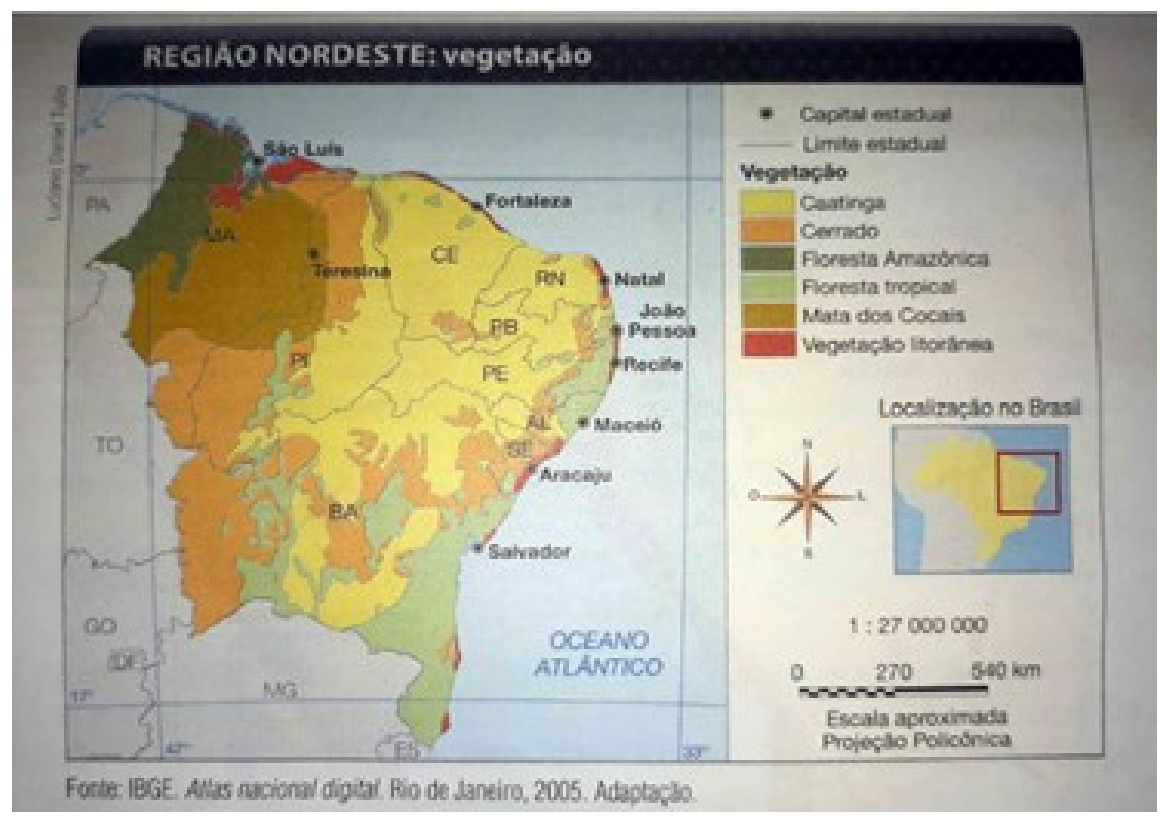

Fonte: Moreira (2014).

Paganelli (2002) aponta que o professor não é um simples manipulador do conhecimento, precisa enfrentar com sucesso a escolha dos conteúdos no seu planejamento curricular. Ser crítico e ter criatividade diante das concepções nas obras e publicações do material didático pela indústria cultural, como também agregar os conceitos geográficos e os conteúdos ao nível dos discentes no processo de ensino aprendizagem.

O LD 4 faz uma abordagem sobre a classificação das caatingas como um domínio. Ele agrega em seus escritos aos locais onde a caatingas são encontradas com base na estrutura do relevo. Em relação à vegetação, o LD 4 destaca a caatinga em sua formação campestre; o uso do termo matas secas; a estrutura arbórea pequena e arbustiva e pontuando a perda das folhas no período de seca. Outro destaque importante é o estímulo ao debate, sobre o potencial que a vegetação tem em se recuperar logo após o período das chuvas e uso da flora pelas famílias para sua comercialização (fibras, óleos vegetais e ceras) (Figura 7). 
Figura 7 - Paisagem da caatinga no período de seca e após as precipitações pluviométricas no LD4

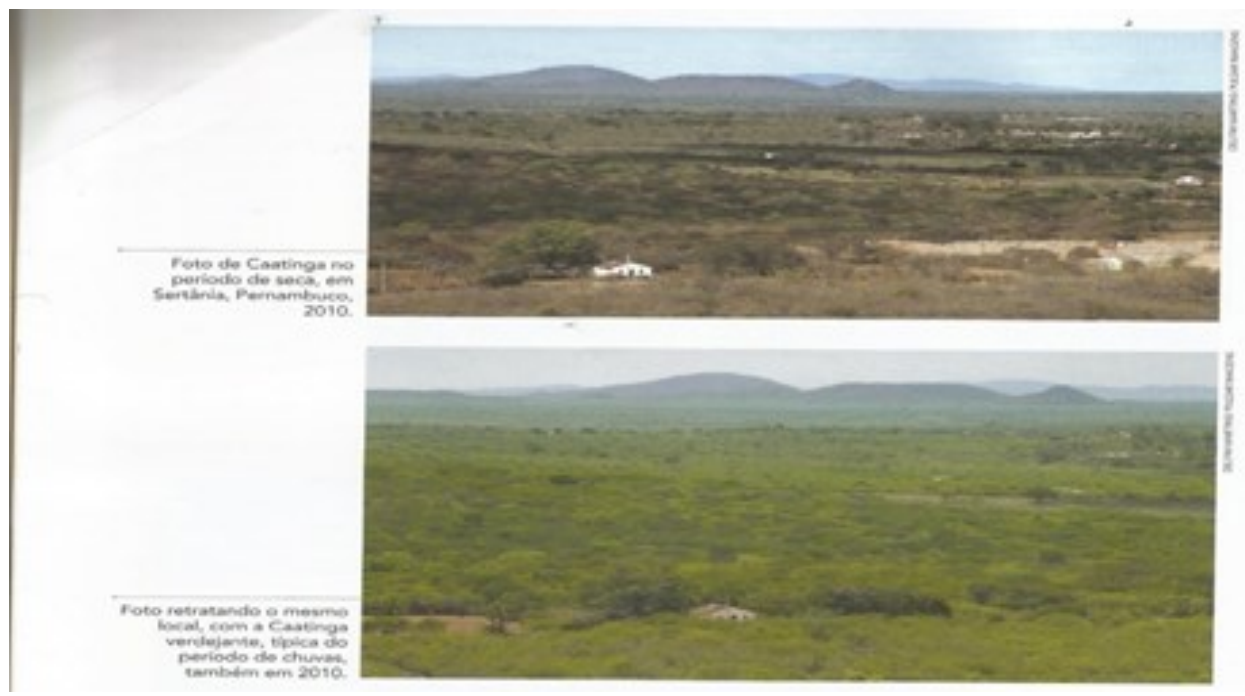

Fonte: Giardiano et al. (2015).

Na Base Nacional Comum Curricular (BNCC) comenta que se deve caracterizar a Caatinga com seus aspectos físicos naturais, sua distribuição e biodiversidade no território brasileiro, como também as unidades de conservação para proteger esse bioma/domínio (BRASIL, 2018). Contudo, não faz uma abordagem social das populações que ali estão inseridas, nem do uso e ocupação das terras, problemas ambientais como desertificação, desmatamento e queimadas para a mineração.

Com essas temáticas debatidas em sala de aula, o docente instrui seres humanos que empregarão a Geografia ao longo de sua vida com uso diário dos conhecimentos geográficos, que foi mediado pelo livro (SCHÄFFER, 2002). A exemplo das paisagens litorâneas, uso e ocupação dessas áreas pelos turistas e as caatingas pelo uso sustentável e extração da madeira.

Pontuschka (1999) pontua que a Geografia - enquanto disciplina escolar - está no jogo dialético entre a realidade da sala de aula e da escola, entre as transformações históricas da produção geográfica na academia e as várias ações governamentais representadas, hoje, por guias, pelos Parâmetros Curriculares Nacionais - PCNs, a Base Nacional Comum Curricular - BNCC. Tudo isto sem proporcionar mudanças radicais na estrutura da escola e na organização pedagógica global.

Soma-se a essas questões, a ausência de transmissão de conteúdos que se aproximem da realidade do aluno, fato que pode corroborar para o desinteresse pelo aprendizado geográfico, sendo imprescindível uma superação do que se está posto. Isto inclui uma visão crítica dos pontos que compõem tanto o livro didático quanto o currículo. 
O ensino de Geografia e a aula de campo adaptam distintas possibilidades metodológicas que podem ser empregadas por docentes da rede pública e privada, preparados a agenciar aos seus alunos um ensino eficaz, interativo e reflexivo, para que a teoria possa ser desenvolvida na aula de campo (SILVA, CAVALCANTI, 2016; JESUS, SANTOS, 2019). Exemplos de aula de campo podem ser desenvolvidas em área de caatinga na Serra da Santa-Petrolina para observação dos solos e vegetação com ficha para catalogar as espécies nativas. Como também na região da chapada Diamantina-Bahia para fotografar os pássaros da caatinga e identificar as espécies da flora nas áreas de transição entre caatinga, cerrado e mata atlântica.

\section{CONSIDERAÇÕES FINAIS}

Importa que os recursos didáticos, em especial os livros, possam promover um aprendizado contextualizado entre o conteúdo descrito e o cotidiano do aluno.

Nos estudos relacionados ao conteúdo físico geográfico, as relações homem-meio devem ser valorizadas para além da simples memorização dos conteúdos. Isto favorece uma educação, de fato, significativa.

Nesse sentido, foram analisados 4 livros didáticos da educação básica fundamental - 3 do período em que os PCNs estavam vigorando e um escrito dentro das normas da nova BNCC - a fim de averiguar como os temas relacionados a dois grandes e relevantes sistemas naturais, o litoral e o sertão, foram tratados nessas obras.

No LD1, foi constatado que os conceitos físicos são muito utilizados e as relações natureza e sociedade, no litoral, são observadas em menor intensidade. Além disso, o termo "oceânico" e a dinâmica desse sistema são mais trabalhados do que as nomenclaturas "litoral", "costa" e a presença antrópica nesses ambientes, distinguindo-se, de certa forma, do que é proposto nos PCNs, onde instrui que a observação e a caracterização dos elementos presentes na paisagem é o início de uma compreensão mais ampla das relações entre sociedade e natureza. Tal instrução corrobora no sentido de se construir uma educação, cada vez mais, contextualizada.

No LD2, foi dada ênfase ao contexto físico do litoral voltando-se para a descrição da morfologia praial e suas modificações por influência do fator hidrodinâmico. As relações do homem como grande agente transformador da paisagem costeira, de forma histórica e atual, não foram observadas. 
Foi constatado também que nos livros didáticos LD 3 e LD 4, que abordam a caatinga, o conteúdo é escasso, dando pouca atenção a caatinga, abordando mais questões ligadas ao desenvolvimento agropecuário, citando, em dados momentos, a vegetação. Contudo, é necessária uma abordagem sistêmica dos fatores condicionantes para esta formação natural, como também da população que reside na região.

Sugere-se que alternativas, o uso de produção de materiais paradidáticos dos temas do litoral e caatinga seja construído para aprendizagem significativa dos discentes, como também uso de jogos; manuais; aplicativos educacionais ligados ao conteúdo. Além disso, mostra-se interessante, se possível, dar ênfase a atividades de campo em áreas litorâneas e de Caatinga para o desenvolvimento prático dos conteúdos trabalhos em sala.

\section{REFERÊNCIAS}

AB' SABER, A. N. Os domínios de natureza no Brasil: potencialidades paisagísticas. São Paulo: Ateliê Editorial, 2003.

ALBUQUERQUE, U. P.; MELO, F. P. L. Socioecologia da Caatinga. Ciência e Cultura, v. 70, n. 4, p. 40-44, 2018.

BRASIL. Base Nacional Comum Curricular. Educação é a Base. Brasília: MEC, 2018.

BRASIL. Censo Demográfico. IBGE (2010).

BRASIL. Secretaria de Educação Fundamental. Parâmetros curriculares nacionais: Geografia. Brasília: MEC/SEF, 1998.

BRASIL. RESOLUÇÃ̃ CIRM No 5, de 3 de dezembro de 1997. Aprova o Plano Nacional de Gerenciamento Costeiro II (PNGC II), 1997.

BRASILEIRO, R. S. Alternativas de desenvolvimento sustentável no semiárido nordestino: da degradação à conservação. SCIENTIA PLENA, v. 5, n. 5, 2009, p. 1-12.

CALLAI, H. C. O ensino de geografia: recortes espaciais para análise. In: CASTROGIOVANNI, A. C.; CALLAI, H. C.; SCHAFFER, N.O.; KAERCHER, N. A. (Orgs.). Geografia em sala de aula práticas e reflexões. Editora da UFRGS, 199p., 2003.

CASTROGIOVANNI, A. C.; GOULART, L. B. A questão do livro didático em Geografia: elementos para análise. In: CASTROGIOVANNI, A. C.; CALLAI, H. C.; SCHAFFER, N.O.; KAERCHER, N. A. (Orgs.). Geografia em sala de aula - práticas e reflexões. Editora da UFRGS, 199p., 2003.

CAVALCANTI, L. C. S. Cartografia de paisagens: fundamentos. 2 ed. rev. e atual. São Paulo: Oficina de Textos, 2018.

FILHO, G. G. J. CAMILLO, J. S. O Uso racional do mar in Geografia: ensino fundamental e ensino médio; o mar no espaço geográfico brasileiro. Ministério da Educação, Brasília, 2006. v. 8. 304 p.

FREITAS, J. Paisagens simbólicas do litoral: antigas leituras, novas tradições, 2013. 
GIARDIANO, C.; ORTEGA, L. M.; ORTONELA, J.;CHIANCA, R.B.;CARVALHO, V. Geografia nos dias de hoje 7 ano. Leya: São Paulo, 2015.

JESUS, M. C. S.; SANTOS, M. F. A aula de campo no ensino da geografia: experiências cotidianas na cidade para construção de aprendizagens. Revista Ensino de Geografia (Recife), v. 2, n. 1, p. 187- 198, 2019.

GIL, A. C. Métodos e técnicas de pesquisa social. 5. ed. São Paulo: Atlas, 1999.

MAGAlHÃES, T. Caatinga: um bioma exclusivamente brasileiro e o mais frágil. Revista do Instituto Humanista. n.389, 2012.

MOREIRA, I. Conquista: Solução Educacional Positivo: Geografia, $6^{\circ}$ ano. - Curitiba: Positivo, 2014.

MOREIRA, I. Conquista: Solução educacional. Positivo: Geografia $7^{\circ}$ ano, Curitiba: Positivo, 2014.

OLIVEIRA, L. O ensino/aprendizagem de Geografia nos diferentes níveis de ensino. In: PONTUSCHKA, N. N.; OLIVEIRA, A. U. (Orgs.). Geografia em perspectiva. Contexto, 383p., 2002.

PAGANELLI, T. I. Reflexões sobre categorias, conceitos e conteúdos geográficos: seleção e organização. In: PONTUSCHKA, N. N.; OLIVEIRA, A. U. (Orgs.). Geografia em perspectiva. Contexto, 383p., 2002.

PONTUSCHKA, N. N. Geografia: pesquisa e ensino. In: Carlos, A. F. A. (org.), Novos Caminhos da Geografia. 5. ed. São Paulo: Contexto, 2005.

PRADO, D. E. As caatingas da América do Sul. In: LEAL, I. R.; TABARELLI, M.; SILVA, J. M. C. Ecologia e conservação da caatinga. Recife: EUFPE, 2003.

ROCHA, A. P. P. Caatinga: abordagem em livros didáticos de Geografia no Sertão Pernambucano. 16 f. Monografia (Graduação em Geografia) - Universidade de Pernambuco, Petrolina, 2018.

SANTOS, A. M.; GALVÍNCIO, J. D. Mudanças climáticas e cenários de susceptibilidade ambiental à desertificação em municípios do estado de Pernambuco. Observatorium, v.5, p.66-83, 2013.

SCHÄFFER, N. O. O livro didático e o desempenho pedagógico: anotações de apoio à escolha do livro texto. In: CASTROGIOVANNI, A. C.; CALLAI, H. C.; SCHAFFER, N.O.; KAERCHER, N. A. (Orgs.). Geografia em sala de aula - práticas e reflexões. Editora da UFRGS, 199p., 2003.

SELBACH. S. Geografia e didática. Petrópolis, RJ: Vozes, 2010.

SILVA, F. P.; CAVALCANTI, L. C. S. Convivência com o semiárido: práticas interdisciplinares com alunos de uma escola pública em Petrolina/PE. Revista Brasileira de Educação em Geografia, v. 6, p. 405-412, 2016.

SILVA, F. P.; SANTOS, A. M. O Domínio das Caatingas trabalhado nos livros didáticos de geografia. Élisée - Revista de Geografia da UEG, v. 7, n. 02, p. 20-39, 31, 2018.

SILVA, F. P.; MOURA, G. J. B.; SANTOS, C. A. B. Representações dos moradores do entorno das áreas de exploração sobre a importância e impactos da mineração. Geosul, Florianópolis, v. 33, n. 66, p. 128-146, 2018. 
SILVA, J. M. C.; BARBOSA, L. C. F.; LEAL, I. R.; TABARELLI. The Caatinga: Understanding the Challenges. In: SILVA, J. M. C.; LEAL, I. R.; TABARELLI (Orgs.). Caatinga The Largest Tropical Dry Forest Region in South America. Springer, p. 3-22, 2017.

SOUZA, B. I.; ARTIGAS, R. C.; LIMA, E. R. V. Caatinga e desertificação. Mercator, v.14, n.1, p.131-150, 2015.

SPOSITO, M. C. As diferentes propostas curriculares e o livro didático. In: PONTUSCHKA, N. N.; OLIVEIRA, A. U. (Orgs.). Geografia em perspectiva. Contexto, 383p., 2002.

TABARELLI, M.; LEAL, I.R.; SCARANO, F.R.; SILVA, J.M.C. Caatinga: legado, trajetória e desafios rumo à sustentabilidade. Ciência e Cultura, v. 70, n. 4, 25-29, 2018.

VASCONCELOS, F. P. Gestão Integrada da Zona Costeira: Ocupação antrópica desordenada, erosão, assoreamento e poluição ambiental do litoral. Fortaleza. Premius, 2005. 88 p.

VELOSO, A. L.; SAMPAIO, E. V. S. B.; PAREYN, F. G. C. Ecorregiões Propostas para o Bioma Caatinga. Recife: Associação Plantas do Nordeste; Instituto de Conservação Ambiental do Brasil, 2002.

WERNECK, F. P. The diversification of eastern South American open vegetation biomes: Historical biogeography and perspectives. Quaternary Science Reviews, n. 30, p. 1630-1648, 2011. 